University of Nebraska - Lincoln

DigitalCommons@University of Nebraska - Lincoln

Biochemistry -- Faculty Publications

Biochemistry, Department of

2009

\title{
Hyaluronan-Binding Proteoglycans
}

\author{
Ed Harris \\ University of Nebraska - Lincoln, eharris5@unl.edu
}

Paul H. Weigel

University of Oklahoma Health Sciences Center, paul-weigel@ouhsc.edu

Follow this and additional works at: https://digitalcommons.unl.edu/biochemfacpub

Part of the Biochemistry, Biophysics, and Structural Biology Commons

Harris, Ed and Weigel, Paul H., "Hyaluronan-Binding Proteoglycans" (2009). Biochemistry -- Faculty Publications. 66.

https://digitalcommons.unl.edu/biochemfacpub/66

This Article is brought to you for free and open access by the Biochemistry, Department of at DigitalCommons@University of Nebraska - Lincoln. It has been accepted for inclusion in Biochemistry -- Faculty Publications by an authorized administrator of DigitalCommons@University of Nebraska - Lincoln. 
Published (as Chapter 15) in Animal Lectins: A Functional View, edited by Gerardo R. Vasta \& Hafiz Ahmed (Boca Raton: CRC Press, 2009), pp. 223-231. Copyright (C) 2009 Taylor \& Francis Group LLC. Used by permission.

\title{
Hyaluronan-Binding Proteoglycans
}

\author{
Edward N. Harris and Paul H. Weigel
}

Contents
1 Introduction
2 Aggrecan
3 Versican
4 Beurocan
Acknowledgments
References

\section{Introduction}

Molecular components of the extracellular matrix (ECM) are critical for matrix stabilization, cellular differentiation, and tissue morphogenesis. Once thought to function only as the extracellular glue that primarily binds cells together, proteoglycans in the ECM carry out a diverse array of activities and can be grouped into five functionally based families: (i) hyalectins (lecticans), which contain lectin-like carbohydrate-recognition domains (CRDs) and bind hyaluronan (HA); (ii) heparan sulfate (HS) proteoglycans that sequester growth factors via their HS chains; (iii) small leucine-rich proteoglycans (SLRPs) containing leucine-rich domains that interact with collagens and other ECM proteins; (iv) phosphacans that function primarily as receptor-like protein-tyrosine phosphatases; and (v) part-time proteoglycans that reside both on the cell surface and in the ECM. More than 40 cDNAs encoding proteoglycan core proteins have been discovered thus far [1]. For the sake of brevity, this chapter will focus only on the four lecticans that bind HA (Figure 1): Aggrecan, neurocan, brevican, and versican.

All lecticans have two N-terminal Link domains, one immunoglobulin-like module, a central glycosaminoglycan (GAG)-attachment region, and one or more EGF-like domains in the C-terminus. The lecticans are post-translationally modified by O-Linked GAG chains on Ser residues of multiple Ser-Gly dipeptide repeats. Aggrecan, versican, neurocan, and brevican contain 120, 20, 7, and 3 potential sites, respectively. Generally, the CS chains of the lecticans maintain structural integrity of the tissue ECM by serving as barrier functions to limit the growth and migration of cells. For example, the CS chains of neurocan and brevican act as barriers to inhibit neurite outgrowth and migration so that, hypothetically, dendrites are available for longer periods of time in their local environment to make the correct synaptic junctions [2] and set up guidance cues for migration [3,4]. The barrier functions of the lecticans exist on two levels: (i) as mechanical barriers, the proteoglycans form neuronal nets to physically constrain neurite outgrowth [5] and (ii) as cell signaling barriers, the proteoglycans can activate intracellular signaling pathways regulated by the Rho-family GTPases to promote the 


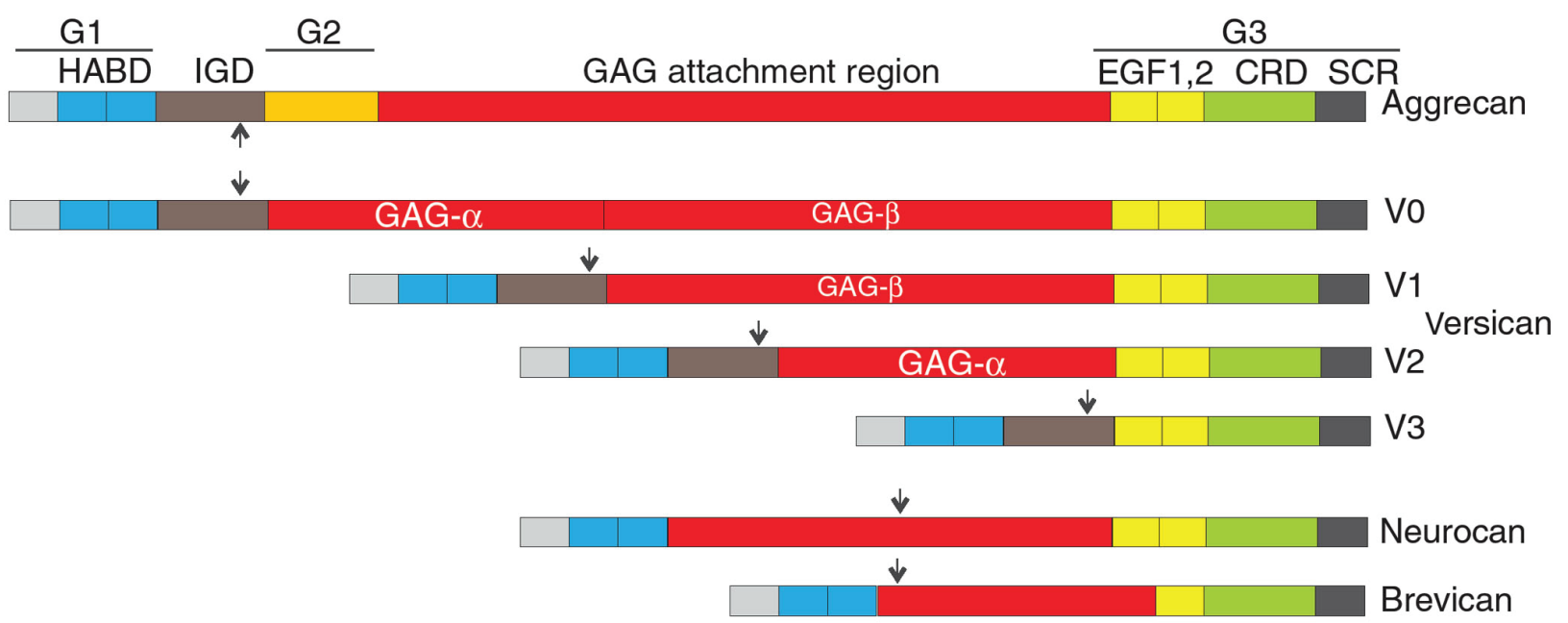

Figure 1. Lectican domain organization. The common domains of the lecticans include two globular domains, G1 and G3, and a CS/KS-attachment region (red). The G1 region contains two Link modules (blue) that bind to HA. The G3 domain contains at least two EGF-like regions (yellow), a carbohydrate recognition domain (CRD; green), and a short complement regulatory region (SRC; black). Glycanated aggrecan is the largest of the lecticans, containing up to 120 CS and KS chains, in addition to an Ig-fold sequence (IGD; brown) and a G2 region (orange). The four splice variants of versican (V0-V3) contain N- and C-terminal regions that are very homologous with aggrecan and differing CS-attachment regions (except for V3) encoded by different exons, which are preferentially spliced depending on the host celltype. Versican V0 contains the longest core protein of all the lecticans and contains up to 20 CS chains. Neurocan, with seven CS chains, and brevican, with three CS chains, differ in size and glycanation and do not contain an Ig-domain (IGD). Metalloproteolyic cleavage sites for ADAMTS-1/4 or MMP-2 (in neurocan only) are represented by the arrows.

disruption of the actin cytoskeleton and growth cone collapse [6]. In addition to the barrier functions, GAGs in close proximity may also serve to sequester water to maintain tissue hydration.

Neurocan and brevican are primarily neural ECM lecticans, whereas aggrecan is found mainly in cartilage and versican is in vascular vessel walls. Aggrecan and versican play minor, albeit important and sometimes transient, functions in central nervous system (CNS) development and ECM composition [7]. Aggrecan, versican, and brevican are proteolytically degraded by ADAMTS-1/4 (a disintegrin and metalloproteinase with thrombospondin motifs) metalloproteases, whereas neurocan is processed by matrix metalloproteinases 2 (MMP-2). Metalloprotease cleavage of the lecticans is part of their normal turnover process and an increase in metalloprotease activity in tissues such as the brain may be a prerequisite for diseases such as Alzheimer's disease and epilepsy [8]. Numerous reviews have described the biology, chemistry, and physiological impact of these lecticans, their splice variants, and their cohorts of interacting partners on matrix and cellular composition in tissues [9-19].

\section{Aggrecan}

Chondrocytes synthesize and secrete the ECM components of cartilage. The most abundant protein is collagen II, which is up to $60 \%$ of the dry weight of the cartilage, followed by aggrecan ( $35 \%$ of dry weight). All other components make up the remaining $5 \%$ of the tissue dry weight [20]. The aggrecan core protein is heavily modified in the endoplasmic reticulum (ER)/Golgi by addition of chondroitin sulfate (CS) and keratan sulfate (KS) chains prior to secretion from the cell. These glycosaminoglycan (GAG) modifications greatly increase the molecular mass of the molecule by at least four- to five-fold over the core protein alone. After aggrecan is secreted from chondrocytes, it interacts with HA and Link proteins to form organized structures - proteoglycan aggregates. The CS and KS chains 
are highly sulfated, giving the entire aggrecan molecule a high polyanionic charge, which attracts and binds large amounts of water and cations. Seventy percent of the wet weight of cartilage is due to water sequestered by the high-density negative charge associated with the sulfate and carboxylate groups on the GAGs, giving the tissue a gel-like quality [21]. The viscoelastic behavior of the GAGs in aggrecanHA aggregates is directly responsible for the unique physical properties of articular cartilage, which includes compressive resilience during joint loading and load distribution over the surface of the tissue.

The aggrecan core protein consists of three disulfide-bonded globular domains, G1, G2, and G3, and a GAG-attachment region, primarily containing CS (Figure 1). The N-terminus of the G1 domain contains the HA-binding regions, which consist of two Link domains of $\sim 93$ amino acids with homology to the Link domains found in other hyalectins such as the hyaluronic acid receptor for endocytosis (HARE), TSG-6, CD44, and lymphatic vascular endothelial hyaluronan receptor 1 (LYVE-1) (Harris \& Weigel in Vasta \& Ahmed, Animal Lectins [2009], Chapter 12). Another ECM protein called "Link protein" (due to its function of "linking" aggrecan and HA) binds to both HA, with its own Link domain, and the G1 domain of aggrecan via an Ig-fold [22]. This trimeric (HA-Link protein-aggrecan) complex creates a stable and long-lasting three-dimensional structure that is strong, yet flexible enough to withstand the high-impact physical forces constantly experienced by our joints and tissues. Binding studies using surface plasmon resonance show that a fragment of aggrecan comprising G1 and G2 binds HA with a $K_{d}$ of $226 \mathrm{nM}$, whereas the Link protein binds HA with a $K_{d}$ of $89 \mathrm{nM}$, a higher affinity [23].

The G2 domain shares some structural features with G1, but lacks the ability to bind HA. It is heavily substituted with KS chains and N-terminally adjacent to the CS attachment region. Both G1 and G2 domains inhibit aggrecan monomer secretion until the protein is fully modified and correctly folded. On the other hand, the G3 domain is known to promote secretion of the monomer and progression of the protein along the secretory pathway after GAG addition [24]. The region between the G1 and G2 domains, the interglobular domain (IGD region), is cleaved by proteolysis during normal aggrecan turnover. Conditions in which there is an increased exposure to, or expression of, inflammatory cytokines (e.g., as found in arthritis) promote the degeneration of aggrecan and weakening of the cartilage. The loss of the G2 through G3 portion of aggrecan changes the physicochemical attributes of the HA-aggrecan aggregate structure, which is difficult to repair, since the G1 domain fragment may remain bound to HA and thus prevent the binding of newly synthesized intact aggrecan monomers with HA [25-27].

The G3 or C-terminal domain of aggrecan contains two EGF-like domains (EGF1 and EGF2), a $\mathrm{CRD}$, and a complement regulatory protein B component or short complement repeat (SCR). The primary role of the G3 domain is to aid secretion of the aggrecan monomer from chondrocytes after protein synthesis and GAG assembly in the ER/Golgi. The G3 domain is essentially a cap that prevents degradation, while the individual subdomains within G3 assist with processing, trafficking, and secretion of the heavily glycosylated core protein [28, 29]. The G3 domain in articular cartilage is primarily associated with newly synthesized or immature aggrecan, whereas most mature aggrecan core proteins have lost their G3 domains in age-related processes [30].

Assembly of the aggrecan supramolecular structure is a highly ordered process that begins on the chondrocyte surface. In humans, HA is made at the cell surface by any of the three membranebound HA synthase isozymes (HAS1, 2, or 3) [31-33]. As HA is extruded from the cell surface, newly synthesized aggrecan and Link proteins may bind with the HA to form aggregates. The Link protein is required for proper alignment and ordering of the aggrecan along the HA [34]. The details for how Link protein is secreted and helps assemble these structures are not known. Furthermore, since cartilage is an acellular tissue, special processes are needed to facilitate the assembly of new ECM components many cell diameters away from the site of synthesis. One facilitation mechanism is that not all immature aggrecan monomers can bind HA, which is advantageous for development, since these aggrecan monomers then have time to travel away from the cell (i.e., the site of synthesis) before they become anchored to a HA molecule. This delayed incorporation of aggrecan may be the result of structural changes in the G1 domain $[35,36]$, or the interaction of the G3 domain with other 
ECM structural proteins such as fibulin $1 / 2$, tenacin-C and tenacin- $\mathrm{R}$ [37]. Unincorporated aggrecan has a short half-life, $24 \mathrm{~h}$ or less, whereas aggrecan incorporated into HA aggregates has a half-life of many years [38]. The immature unassociated aggrecan monomer needs to undergo several physical changes, depending on the environment, or it will be degraded. Once aggrecan binds with HA and Link protein, the molecule is very stable and can proceed to assemble into supramolecular aggregates with other aggrecan and ECM molecules such as biglycan, decorin, fibulin, and the collagens.

\section{Versican}

Human versican is a "versatile" molecule found in the ECM of connective tissues and the ECMs of a wide variety of "soft" tissues, including brain, arterial and venous vasculature, epithelia, and mesenchyme. The full-length core protein is the longest of the four lecticans, discussed in this chapter, and is encoded by a gene that extends over $100 \mathrm{~kb}$ and includes 15 exons. The core protein is organized in a fashion similar to the other lecticans (Figure 1) with a HA-binding globular G1 domain at the N-terminus and two GAG attachment domains, termed GAG- $\alpha$ and GAG- $\beta$, in the middle region encoded by 3 and $5.3 \mathrm{~kb}$ exons, respectively. The $\mathrm{C}$-terminal portion of the protein contains two EGF-like domains, a CRD and a complement regulatory region. Alternative splicing of versican results in three variants (termed V1, V2, and V3), as well as full-length (V0), that are encoded by 3, 9, 6.5, and $12 \mathrm{~kb}$ transcripts, respectively. The molecular masses for these variants (V0-V3) are 370, 262, 180 , and $72 \mathrm{kDa}$. V1 does not include GAG- $\alpha$, V2 does not contain GAG- $\beta$, andV3 lacks both GAG attachment regions and is, therefore, technically not a proteoglycan [19].

Versican is the major proteoglycan in most arteries and veins, where it interacts with HA and Link proteins to form stable high molecular mass aggregates that fill spaces not occupied by other proteins such as collagen and elastin. The interaction of versican with other proteins and HA provide the blood vessels with walls that are both firm and elastic, thus able to contract or dilate in response to blood pressure, temperature changes, etc. In addition to normal turnover, inflammation and aging promote the degradation of versican, a process in which the core protein is cleaved by members of the ADAMS-TS metalloproteases family, in addition to matrilysin and plasmin. The loss of versican in the blood vessel walls may contribute to a weakening of the overall structure, giving rise to aneurysms and pseudoaneurysms $[39,40]$.

Arterial smooth muscle cells (ASMC) are the primary source of versican in both arteries and blood vessels and express the transcripts to produce V0, V1, and V3 [41, 42]. Platelet-derived growth factor, through the MAP kinase pathway, stimulates an increase in versican core protein transcription and CS chain elongation [43]. Conversely, IL-1 $\beta$ produced by inflammatory-stimulated macrophages decreases versican expression, suggesting that macrophage binding to vasculature lesions may contribute to the versican breakdown associated with this pathology [44]. Versican enriched with CS-6 and CS- 4 chains is involved in the advanced stages of atherosclerotic lesions. Versican is prominent near the edges of necrotic cores and in close proximity to lipoproteins [45]. In vitro binding studies demonstrate that multiple low-density lipoprotein (LDL) particles can bind to single CS chains with an affinity of $23 \mathrm{nM}$, and an increase in chain length directly correlates with increased binding of LDL particles with the same affinity $[18,46]$. Treatment of ASMCs with growth factors such as EGF and TGF- $\beta$ also causes elongation of CS chains on versican and may serve as a positive feedback stimulus in the early stages of atherogenesis $[47,48]$.

The increased expression of versican V2, a product of oligodendrocytes, occurs in the periphery of brain lesions. In vitro cultures of oligodendrocytes indicate that the expressed versican acts as a linker between HA and tenascin-R, forming a rudimentary ECM. Axon regeneration failure is induced due to this injury response, since versican mediates growth-cone collapse and growth inhibition through its CS chains and core protein sequence [49]. Since all of the lecticans, including versican, present in the brain are growth-inhibitory, several methods to eliminate versican have been devised in order to 
promote axon regeneration. These include the use of antiversican antibodies to eliminate versican expressing cells via complement-killing in the rat [50] and the infusion of antimitotic agents to prevent oligodendrocyte recruitment to the lesion [51].

\section{Neurocan}

The rat brain proteoglycan, neurocan, was identified and characterized using monoclonal antibodies [52]. During embryonic development, neurocan is commonly found as a $250 \mathrm{kDa}$ monomer, and then later during maturation, it occurs as two protein isoforms of 130 and $150 \mathrm{kDa}$ due to proteolysis at a MMP-2 cleavage site [53]. The N-terminal $130 \mathrm{kDa}$ segment is the major HA-binding component and contains two CS chains, while the C-terminal $150 \mathrm{kDa}$ segment binds with other ECM proteins and calcium ions [54]. Expression of neurocan is confined to the CNS, although it is present in the developing sensory nerves of the optical and olfactory systems in lower animals [55, 56]. In mature brain, the expression of neurocan is very low, but is markedly increased in areas undergoing matrix remodeling. In fact, expression of neurocan may be required for remodeling of hippocampal synaptic connections during learning and memory-induced changes in synaptic transmissions [57].

Neurocan interacts with other molecules via the core protein, its GAG chains, or both. Interacting partners of neurocan can be classified into three different groups. First, the matrix proteins tenascin-C and tenascin-R are important for ECM aggregation during brain development when neurocan and heparin, which enhances the activity, are localized to perineuronal nets (PNNs) [58, 59]. Second, growth factors associated with mobility such as FGF-2 [60], HB-GAM, and amphoterin [61] interact with neurocan and also bind heparin. Binding with amphoterin and HB-GAM is CS-chain dependent in contrast to FGF-2, which binds to the core protein. These growth factors support neurite outgrowth and extension in the developing brain, whereas neurocan serves as a modulator for these growth factors. Third, neural cell adhesion molecules such as N-CAM, L1/Ng-CAM, and TAG-1/axonin- 1 are involved with neurite outgrowth and navigation. Binding of these cell adhesion molecules is CS-dependent, although there is weak binding to the C-terminal portion of the core protein.

Although neurocan interacts with a wide variety of adhesion, growth, and matrix molecules, the neurocan knockout mouse does not exhibit any gross anatomical brain pathologies [62]. Despite the involvement of neurocan in modeling of the CNS matrix, the proteoglycan is not required for the final outcome of how the brain structure develops. Thus far, the phenotypes of neurocan deficiency have only been observed in mice and give no indication of the possible affects on higher-brain functions such as thought and reasoning. Interestingly, an L1/Ng-CAM deficiency causes mental retardation in humans, but causes no physical or mental manifestation in mice, proving that not all animal models reflect the human condition [63].

\section{Brevican}

Expression of brevican or brain-enriched hyaluronan-binding protein (BEHAB) is restricted to the brain and is particularly enriched in neuroglial sheaths of velate protoplasmic astrocytes in the cerebellar granular layer [64] and in PNNs of large neurons [65]. In the rat, brevican is expressed at high levels in the neuroaxis of the ventricular zones and may be important for the development of glial cells. Brevican was first discovered in rats and cats as a partial protein with a molecular mass of $\sim 38$ $\mathrm{kDa}$ [66]. The full-length $160 \mathrm{kDa}$ core protein is now known to be proteolytically cleaved, resulting in two physiologically relevant fragments of 100 and $60 \mathrm{kDa}$ [67].

The ECM of the brain contains cross-linking proteins called the tenascins, which serve not only as part of the lattice that supports the neuronal network of the brain, but also as coregulators of morphogenesis and remodeling associated with injury, learning, and growth. Neurocan binds strongly 
with tenascin- $\mathrm{C}$, and both proteins increase in expression during tissue regeneration [68]. On the other hand, brevican binds with tenascin-R via its fibronectin III domain in a CS-independent manner [69]. Tenascin-R, HA, and the lecticans, especially brevican and neurocan, are basic components of the PNNs first described by Camillo Golgi and Santiago Ramon y Cajal in the 1890s. Neurons and glial cells secrete the materials that compose the PNN, which is a reticular net-like feature covering these cells that forms the organized lattice material in the intercellular spaces [65]. The PNN, which is structurally similar in some ways to the aggrecan-HA proteoglycan aggregates of cartilage, provides a tougher shield to protect the enclosed neurons and glial cells from movement within an otherwise vulnerable soft tissue matrix.

Brevican is a unique marker for glioma, a type of cancer that originates within the glial cells of the brain and metastasizes very extensively within the cranial ECM, but does not extend outside the CNS boundaries [70]. One of the main features of a high-grade glioma is the presence of an underglycosylated form of brevican $\left(\mathrm{B} / \mathrm{b}_{\Delta \mathrm{g}}\right)$, which migrates at $150 \mathrm{kDa}$ on sodium dodecyl sulfate polyacrylamide gel electrophoresis (SDS-PAGE). Other forms of brevican are also present, such as a differentially glycosylated form that migrates slightly larger than $160 \mathrm{kDa}$ and the proteolytic byproducts of ADAMTS-4-induced cleavage of the native protein [71-73]. These features are not present in other neuropathologies such as Alzheimer's disease, nonglial tumors, or Parkinson's disease. Like the other lecticans, brevican exerts its inhibitory control on neurite outgrowth and cell migration via it $\mathrm{CS}$ chains. Brevican $\left(\mathrm{B} / \mathrm{b}_{\Delta \mathrm{g}}\right)$, a likely agent for glioma aggressiveness, may tip the balance in the favor of growth and migration of neurons.

\section{Conclusion and Future Directions}

Once thought to be ECM components that only hold tissues and organs in place, the lecticans are increasing recognized as dynamic molecules that influence cell behaviors through effector protein/ GAG interactions and signaling pathways. The underlying causes of many intrinsic human diseases, such as Alzheimer's disease and stenosis, can be traced to a "malfunction" of one or more lecticans. The binding partners and matrix associations of this class of molecules are fairly well understood. More exciting future directions will focus on gene regulation and the development of transgenic mice with reporter genes inserted within the promoter regions of versican, brevican, and neurocan. Since little is known about the cis or trans regulatory elements of how these genes are turned on or off, the expression of reporter genes in conjunction with lectican expression will provide answers to questions such as how protein expression corresponds with injury or disease and what regulates that expression. Since the versican knockout is lethal in mice, reporter genes in this model and others will aid our understanding of gene expression during development, disease, and injury and may ultimately provide targets for gene therapeutic interventions.

\section{Acknowledgments}

We acknowledge support by National Institute of General Medical Sciences grants GM69961, GM35978, and F32GM070262 from the National Institutes of Health.

\section{References}

1. N. B. Schwartz, E. W. Pirok, J. R. Mensch, and M. S. Domowicz, Domain organization, genomic structure, evolution, and regulation of expression of the aggrecan gene family. Prog Nucleic Acid Res Mol Biol 62, 177-225, 1999.

2. P. A. Brittis, D. R. Canning, and J. Silver, Chondroitin sulfate as a regulator of neuronal patterning in the retina. Science 255, 733-736, 1992. 
3. D. M. Snow, D. A. Steindler, and J. Silver, Molecular and cellular characterization of the glial roof plate of the spinal cord and optic tectum: A possible role for a proteoglycan in the development of an axon barrier, Dev Biol 138, 359-376, 1990.

4. D. M. Snow, M. Watanabe, P. C. Letourneau, and J. Silver, A chondroitin sulfate proteoglycan may influence the direction of retinal ganglion cell outgrowth, Development 113, 1473-1485, 1991.

5. T. Murakami and A. Ohtsuka, Perisynaptic barrier ofproteoglycans in the mature brain and spinal cord, Arch Histol Cytol 66, 195-207, 2003.

6. A. Sandvig, M. Berry, L. B. Barrett, A. Butt, and A. Logan, Myelin-, reactive glia-, and scar-derived CNS axon growth inhibitors: Expression, receptor signaling, and correlation with axon regeneration, Glia 46, 225-251, 2004.

7. D. Carulli, K. E. Rhodes, D. J. Brown, T. P. Bonnert, S. J. Pollack, K. Oliver, P. Strata, and J. W. Fawcett, Composition of perineuronal nets in the adult rat cerebellum and the cellular origin of their components, J Comp Neurol 494, 559-577, 2006.

8. K. Satoh, N. Suzuki, and H. Yokota, ADAMTS-4 (a disintegrin and metalloproteinase with thrombospondin motifs) is transcriptionally induced in beta-amyloid treated rat astrocytes, Neurosci Lett 289, 177-180, 2000.

9. Y. Yamaguchi, Lecticans: Organizers of the brain extracellular matrix, Cell Mol Life Sci 57, 276-289, 2000.

10. J. Dudhia, Aggrecan, aging and assembly in articular cartilage. Cell Mol Life Sci 62, 2241-2256, 2005.

11. U. Rauch, Extracellular matrix components associated with remodeling processes in brain. Cell Mol Life Sci 61, 2031-2045, 2004.

12. N. B. Schwartz and M. Domowicz, Proteoglycans in brain development, Glycoconj J 21, 329-341, 2004.

13. U. Rauch, K. Feng, and X. H. Zhou, Neurocan: A brain chondroitin sulfate proteoglycan. Cell Mol Life Sci 58,18421856, 2001.

14. U. Hartmann and P. Maurer, Proteoglycans in the nervous system - The quest for functional roles in vivo, Matrix Biol 20, 23-35, 2001.

15. A. Oohira, F. Matsui, Y. Tokita, S. Yamauchi, and S. Aono, Molecular interactions of neural chondroitin sulfate proteoglycans in the brain development, Arch Biochem Biophys 374, 24-34, 2000.

16. C. E. Bandtlow and D. R. Zimmermann, Proteoglycans in the developing brain: New conceptual insights for old proteins, Physiol Rev 80, 1267-1290, 2000.

17. C. L. Nutt, C. A. Zerillo, G. M. Kelly, and S. Hockfield, Brain enriched hyaluronan binding (BEHAB)/brevican increases aggressiveness of CNS-1 gliomas in Lewis rats. Cancer Res 61, 7056-7059, 2001.

18. T. N. Wight and M. J. Merrilees, Proteoglycans in atherosclerosis and restenosis: Key roles for versican, Circ Res 94, 1158-1167, 2004.

19. M. Rahmani, B. W. Wong, L. Ang, C. C. Cheung, J. M. Carthy, H. Walinski, and B. M. McManus, Versican: Signaling to transcriptional control pathways, Can J Physiol Pharmacol 84, 77-92, 2006.

20. M. Venn and A. Maroudas, Chemical composition and swelling of normal and osteoarthrotic femoral head cartilage. I. Chemical composition, Ann Rheum Dis 36, 121-129, 1977.

21. A. Maroudas, H. Muir, and J. Wingham, The correlation of fixed negative charge with glycosaminoglycan content of human articular cartilage, Biochim Biophys Acta 177, 492-500, 1969.

22. P. P. Goetinck, N. S. Stirpe, P. A. Tsonis, and D. Carlone, The tandemly repeated sequences of cartilage link protein contain the sites for interaction with hyaluronic acid, J Cell Biol 105, 2403-2408, 1987.

23. H. Watanabe, S. C. Cheung, N. Itano, K. Kimata, and Y. Yamada, Identification of hyaluronan-binding domains of aggrecan, J Biol Chem 272, 28057-28065, 1997.

24. W. Luo, T. S. Kuwada, L. Chandrasekaran, J. Zheng, and M. L. Tanzer, Divergent secretory behavior of the opposite ends of aggrecan, J Biol Chem 271, 16447-16450, 1996.

25. M. Z. Ilic, C. J. Handley, H. C. Robinson, and M. T. Mok, Mechanism of catabolism of aggrecan by articular cartilage. Arch Biochem Biophys 294, 115-122, 1992.

26. P. Loulakis, A. Shrikhande, G. Davis, and C. A. Maniglia, N-terminal sequence of proteoglycan fragments isolated from medium of interleukin-1-treated articular-cartilage cultures. Putative site(s) of enzymic cleavage, Biochem J 284 (Pt 2), 589-593, 1992.

27. A. Ratcliffe, J. A. Tyler, and T. E. Hardingham, Articular cartilage cultured with interleukin 1-increased release of link protein, hyaluronate-binding region and other proteoglycan fragments, Biochem J 238, 571-580,1986.

28. J. M. Day, A. D. Murdoch, and T. E. Hardingham, The folded protein modules of the C-terminal G3 domain of aggrecan can each facilitate the translocation and secretion of the extended chondroitin sulfate attachment sequence, J Biol Chem 274, 38107-38111, 1999.

29. M. S. Domowicz, E. W. Pirok, III, T. E. Novak, and N. B. Schwartz, Role of the C-terminal G3 domain in sorting 
and secretion of aggrecan core protein and ubiquitin-mediated degradation of accumulated mutant precursors, $\mathrm{J}$ Biol Chem 275, 35098-35105, 2000.

30. J. Dudhia, C. M. Davidson, T. M. Wells, D. H. Vynios, T. E. Hardingham, and M. T. Bayliss, Age-related changes in the content of the C-terminal region of aggrecan in human articular cartilage, Biochem J 313 (Pt 3), 933-940,1996.

31. P. H. Weigel, Functional characteristics and catalytic mechanisms of the bacterial hyaluronan synthases, Int Union Biochem Mol Biol 54, 201-210, 2002.

32. P. H. Weigel, V. C. Hascall, and M. Tammi, Hyaluronan synthases, J Biol Chem 272,13997-14000,1997.

33. N. Itano and K. Kimata, Mammalian hyaluronan synthases, IUBMB Life 54, 195-199, 2002.

34. M. Morgelin, D. Heinegard, J. Engel, and M. Paulsson, The cartilage proteoglycan aggregate: Assembly through combined protein-carbohydrate and protein-protein interactions, Biophys Chem 50, 113-128, 1994.

35. L. I. Melching and P. J. Roughley, Studies on the interaction of newly secreted proteoglycan subunits with hyaluronate in human articular cartilage, Biochim Biophys Acta 1035, 20-28, 1990.

36. J. A. Buckwalter, J. C. Pita, F. J. Muller, and J. Nessler, Structural differences between two populations of articular cartilage proteoglycan aggregates, J Orthop Res 12, 144-148, 1994.

37. A. Lundell, A. I. Olin, M. Morgelin, S. al Karadaghi, A. Aspberg, and D. T. Logan, Structural basis for interactions between tenascins and lectican C-type lectin domains: Evidence for a crosslinking role for tenascins. Structure 12, 1495-1506, 2004.

38. M. T. Bayliss, S. Howat, C. Davidson, and J. Dudhia, The organization of aggrecan in human articular cartilage. Evidence for age-related changes in the rate of aggregation of newly synthesized molecules, J. Biol. Chem. 275, 6321-6327, 2000.

39. A. D. Theocharis, I. Tsolakis, A. Hjerpe, and N. K. Karamanos, Human abdominal aortic aneurysm is characterized by decreased versican concentration and specific downregulation of versican isoform $\mathrm{V}(0)$, Atherosclerosis 154, 367-376, 2001.

40. A. P. Burke, H. Jarvelainen, F. D. Kolodgie, A. Goel, T. N. Wight, and R. Virmani, Superficial pseudoaneurysms: Clinicopathologic aspects and involvement of extracellular matrix proteoglycans, Mod Pathol 17, 482-488, 2004.

41. T. N. Wight and V. C. Hascall, Proteoglycans in primate arteries. III. Characterization of the proteoglycans synthesized by arterial smooth muscle cells in culture, J Cell Biol 96, 167-176, 1983.

42. V. Asundi, K. Cowan, D. Matzura, W. Wagner, and K. L. Dreher, Characterization of extracellular matrix proteoglycan transcripts expressed by vascular smooth muscle cells, Eur J Cell Biol 52, 98-104, 1990.

43. E. Schonherr, H. T. Jarvelainen, L. J. Sandell, and T. N. Wight, Effects of platelet-derived growth factor and transforming growth factor-beta 1 on the synthesis of a large versican-like chondroitin sulfate proteoglycan by arterial smooth muscle cells, J Biol Chem 266, 17640-17647, 1991.

44. I. J. Edwards, W. D. Wagner, and R. T. Owens, Macrophage secretory products selectively stimulate dermatan sulfate proteoglycan production in cultured arterial smooth muscle cells. Am J Pathol 136, 609-621, 1990.

45. I. Halpert, U. I. Sires, J. D. Roby, S. Potter-Perigo, T. N. Wight, S. D. Shapiro, H. G. Welgus, S. A. Wickline, and W. C. Parks, Matrilysin is expressed by lipid-laden macrophages at sites of potential rupture in atherosclerotic lesions and localizes to areas of versican deposition, a proteoglycan substrate for theáenzyme, Proc Natl Acad Sci USA 93, 9748-9753, 1996.

46. K. L. Olin, S. Potter-Perigo, P. H. Barrett, T. N. Wight, and A. Chait, Lipoprotein lipase enhances the binding of native and oxidized low density lipoproteins to versican and biglycan synthesized by cultured arterial smooth muscle cells, J Biol Chem 274, 34629-34636, 1999.

47. P. J. Little, L. Tannock, K. L. Olin, A. Chait, and T. N. Wight, Proteoglycans synthesized by arterial smooth muscle cells in the presence of transforming growth factor- $\beta 1$ exhibit increased binding to LDLs, Arterioscler Thromb Vase Biol 22, 55-60, 2002.

48. S. Potter-Perigo, C. Baker, C. Tsoi, K. R. Braun, S. Isenhath, G. M. Altman, L. C. Altman, and T. N. Wight, Regulation of proteoglycan synthesis by leukotriene D4 and epidermal growth factor in bronchial smooth muscle cells, Am J Respir Cell Mol Biol 30, 101-108, 2004.

49. R. A. Asher, D. A. Morgenstern, M. C. Shearer, K. H. Adcock, P. Pesheva, and J. W. Fawcett, Versican is upregulated in CNS injury and is a product of oligodendrocyte lineage cells, J Neurosci 22, 2225-2236, 2002.

50. J. K. Dyer, J. A. Bourque, and J. D. Steeves, Regeneration of brainstem-spinal axons after lesion and immunological disruption of myelin in adult rat, Exp Neurol 154, 12-22, 1998.

51. K. E. Rhodes, L. D. Moon, and J. W. Fawcett, Inhibiting cell proliferation during formation of the glial scar: Effects on axon regeneration in the CNS, Neuroscience 120, 41-56, 2003.

52. U. Rauch, P. Gao, A. Janetzko, A. Flaccus, L. Hilgenberg, H. Tekotte, R. K. Margolis, and R. U. Margolis, Isolation and characterization of developmentally regulated chondroitin sulfate and chondroitin/keratan sulfate proteogly- 
cans of brain identified with monoclonal antibodies, J Biol Chem 266, 14785-14801, 1991.

53. F. Matsui, E. Watanabe, and A. Oohira, Immunological identification of two proteoglycan fragments derived from neurocan, a brain-specific chondroitin sulfate proteoglycan, Neurochem Int 25,425-431,1994.

54. J. Stenflo, Y. Stenberg, and A. Muranyi, Calcium-binding EGF-like modules in coagulation proteinases: Function of the calcium ion in module interactions, Biochim Biophys Acta 1477, 51-63, 2000.

55. H. Li, T. C. Leung, S. Hoffman, J. Balsamo, and J. Lilien, Coordinate regulation of cadherin and integrin function by the chondroitin sulfate proteoglycan neurocan, J Cell Biol 149, 1275-1288, 2000.

56. H. J. Clarris, U. Rauch, and B. Key, Dynamic spatiotemporal expression patterns of neurocan and phosphacan indicate diverse roles in the developing and adult mouse olfactory system, J Comp Neurol 423, 99-111, 2000.

57. V. Y. Bolshakov, H. Golan, E. R. Kandel, and S. A. Siegelbaum, Recruitment of new sites of synaptic transmission during the cAMP-dependent late phase of LTP at CA3-CA1 synapses in the hippocampus, Neuron 19, 635-651, 1997.

58. K. Feng, I. Arnold-Ammer, and U. Rauch, Neurocan is a heparin binding proteoglycan, Biochem Biophys Res Commun 272, 449-455, 2000.

59. G. Bruckner, J. Grosche, S. Schmidt, W. Hartig, R. U. Margolis, B. Delpech, C. I. Seidenbecher, R. Czaniera, and M. Schachner, Postnatal development of perineuronal nets in wild-type mice and in a mutant deficient in tenascin-R, J Comp Neurol 428, 616-629, 2000.

60. P. Milev, P. Maurel, A. Chiba, M. Mevissen, S. Popp, Y. Yamaguchi, R. K. Margolis, and R. U. Margolis, Differential regulation of expression of hyaluronan-binding proteoglycans in developing brain: Aggrecan, versican, neurocan, and brevican, Biochem Biophys Res Commun 247, 207-212, 1998.

61. P. Milev, A. Chiba, M. Haring, H. Rauvala, M. Schachner, B. Ranscht, R. K. Margolis, and R. U. Margolis, High affinity binding and overlapping localization of neurocan and phosphacan/protein-tyrosine phosphatase-zeta/beta with tenascin-R, amphoterin, and the heparin-binding growth-associated molecule, J Biol Chem 273, 6998-7005, 1998.

62. X. H. Zhou, C. Brakebusch, H. Matthies, T. Oohashi, E. Hirsch, M. Moser, M. Krug, C. I. Seidenbecher, T. M. Boeckers, U. Rauch, R. Buettner, E. D. Gundelfinger, and R. Fassler, Neurocan is dispensable for brain development, Mol Cell Biol 21, 5970-5978, 2001.

63. T. Brummendorf, S. Kenwrick, and F. G. Rathjen, Neural cell recognition molecule LI: From cell biology to human hereditary brain malformations, Curr Opin Neurobiol 8, 87-97, 1998.

64. H. Yamada, B. Fredette, K. Shitara, K. Hagihara, R. Miura, B. Ranscht, W. B. Stallcup, and Y. Yamaguchi, The brain chondroitin sulfate proteoglycan brevican associates with astrocytes ensheathing cerebellar glomeruli and inhibits neurite outgrowth from granule neurons, J Neurosci 17, 7784-7795, 1997.

65. K. Hagihara, R. Miura, R. Kosaki, E. Berglund, B. Ranscht, and Y. Yamaguchi, Immunohistochemical evidence for the brevican-tenascin- $\mathrm{R}$ interaction: Colocalization in perineuronal nets suggests a physiological role for the interaction in the adult rat brain, J Comp Neurol 410, 256-264, 1999.

66. D. M. Jaworski, G. M. Kelly, and S. Hockfield, BEHAB, a new member of the proteoglycan tandem repeat family of hyaluronan-binding proteins that is restricted to the brain J Cell Biol 125, 495-509, 1994; published erratum appears in J Cell Biol 137(2):521, 1997.

67. H. Yamada, K. Watanabe, M. Shimonaka, M. Yamasaki, and Y. Yamaguchi, cDNA cloning and the identification of an aggrecanase-like cleavage site in rat brevican, Biochem Biophys Res Commun 216, 957-963, 1995.

68. P. L. Jones and F. S. Jones, Tenascin-C in development and disease: Gene regulation and cell function, Matrix Biol 19, 581-596, 2000.

69. A. Aspberg, R. Miura, S. Bourdoulous, M. Shimonaka, D. Heinegard, M. Schachner, E. Ruoslahti, and Y. Yamaguchi, The C-type lectin domains of lecticans, a family of aggregating chondroitin sulfate proteoglycans, bind tenascin-R by protein-protein interactions independent of carbohydrate moiety, Proc Natl Acad Sci USA 94, 1011610121, 1997.

70. F. Thorsen and B. B. Tysnes, Brain tumor cell invasion, anatomical and biological considerations, Anticancer Res 17, 4121-4126, 1997.

71. D. M. Jaworski, G. M. Kelly, and S. Hockfield, The CNS-specific hyaluronan binding protein, BEHAB, is expressed during periods of glial cell generation and motility, Semin Neurosci 8, 391-396, 1996.

72. S. C. Gary, G. M. Kelly, and S. Hockfield, BEHAB/brevican: A brain-specific lectican implicated in gliomas and glial cell motility, Curr Opin Neurobiol 8, 576-581, 1998.

73. M. S. Viapiano, W. L. Bi, J. Piepmeier, S. Hockfield, and R. T. Matthews, Novel tumor-specific isoforms of behab/ brevican identified in human malignant gliomas. Cancer Res 65, 6726-6733, 2005. 